\title{
ISOLATED (FIEDLER'S) MYOCARDITIS
}

\author{
BY \\ H. EVERLEY JONES, O.B.E., M.B., M.R.C.P., and A. G. MARSHALL, M.B., B.Chir. \\ (From The Guest Hospital, Dudley)
}

Isolated myocarditis, since its description by Fiedler in 1899, has received attention abroad, particularly in America and Germany, but no cases seem to have been recorded in this country. It is hoped that this report may stimulate interest in the disease, which may well be less uncommon than hitherto thought.

\section{Case History}

A boy, aged eleven months, was the second child of healthy parents. The mother had been in excellent health throughout her pregnancy, and the patient was a normal baby born naturally at term, weighing $93 \mathrm{lb}$. He was breast-fed for two months and then given a dried milk mixture. Solids were started at three months, and he sat up alone before six months of age. He experienced no illness until July 27 , at the age of nine months, when he refused food and was fretful all night. Next day he was pale and listless and vomited twice. He improved the following day but relapsed the day after, when his doctor could find no definite signs, but put him on sulphonamide (amount unknown, but continued for five days). He remained about the same for several weeks, vomiting most days. During this period he was pale and lifeless but took food fairly well. No dyspnoea was noted, and he was stated never to have been febrile. At no time had he had a cold, and there was no illness in the house at the time.

At the beginning of September he was admitted to hospital. On admission his temperature was $99^{\circ} \mathrm{F}$., pulse 130 , and respirations 50 a minute. He weighed $19 \mathrm{lb}$. He was fretful and faintly cyanosed. The throat and ears were normal. There was no distension of the neck veins. The heart was enlarged, the apex beat being half an inch external to the nipple. Triple rhythm was audible over the whole praecordium, and the sounds were of fair quality. No murmurs were heard. The blood pressure was $110 / 65 \mathrm{~mm}$. Hg. The lungs were resonant throughout, and rhonchi were heard at both bases. The liver was enlarged; the edge, about two inches below the costal margin, was sharp and the surface smooth: it did not appear tender. The spleen was not felt and there was no oedema.

After admission he had periodic attacks of dyspnoea in which he became more cyanosed and suffered from cough. To begin with these attacks lasted about fifteen minutes, but towards the end they became more prolonged and severe. Oxygen administration gave relief. Vomiting occurred at irregular intervals without relation to food, which he took fairly well. The vomiting was never marked until the last twenty-four hours, when dark brown fluid was produced. Throughout his stay in hospital his pulse varied from 116 to 160 per minute and was always regular. The triple rhythm persisted throughout, and the temperature never rose above $99.8^{\circ} \mathrm{F}$. He died in a severe dyspnoeic attack on Sept. 14.

Investigntions. A radiograph of the chest (fig. 1) showed a globular enlargement of the heart. Pericardial paracentesis produced no fluid.

There were $3,810,000$ red cells per c.mm.; the haemoglobin was $8.6 \mathrm{~g}$. per cent.; and white cells 9,300 per c.mm.

A trace of albumin was present in the urine, but examination of three specimens disclosed no sugar or acetone. There was only an occasional leucocyte in the deposit.

The large heart and apparently painless enlargement of the liver suggested a diagnosis of glycogen disease; a blood-sugar curve following the injection of adrenaline showed a small rise, as follows: fasting level $103 \mathrm{mg}$. glucose per $100 \mathrm{ml}$.

$\frac{1}{2}$ hour after adrenaline, $111 \mathrm{mg}$. glucose per $100 \mathrm{ml}$.

1 hour after adrenaline, $108 \mathrm{mg}$. glucose per $100 \mathrm{ml}$

$1 \frac{1}{2}$ hours after adrenaline, $70 \mathrm{mg}$. ghucose per $100 \mathrm{ml}$.

With the repeated absence of acetone from the urine, these findings were considered incompatible with such a diagnosis. Blood cholesterol was $228 \mathrm{mgm}$. per $100 \mathrm{ml}$.

Autopsy. An autopsy was performed within twelve hours of death. Apart from a somewhat protuberant abdomen the body appeared normal. There was no oedema, but $10 \mathrm{ml}$. of clear, dark yellow fluid were present in the peritoneal cavity. There was no pleural nor pericardial effusion.

The heart weighed $110 \mathrm{~g}$. (normal $40 \mathrm{~g}$.). Both ventricles and auricles were somewhat dilated, and their walls thickened. The endocardium of the left auricle was grossly thickened. The myocardium was bright red and was rather hard in consistency No mural thrombi nor vegetations were present, and the valves were normal, though the chordae 
tendineae of the mitral valve appeared unusually short. There were no congenital defects (fig. 2).

The liver (390 g.; normal 277 g.) showed the appearance found in chronic venous congestion. The spleen ( 30 g.) was firm and engorged. Apart from a small patch of consolidation on the anterior border of the right lower lobe, the lungs showed only engorgement; there was no pulmonary oedema.

The remaining organs were found to be within normal limits.

Histology. A complete histological examination was carried out. In view of the suspicion of glycogen disease, portions of liver, kidney, and pancreas were fixed in alcohol and stained specifically for glycogen. None was found.

Sections were cut from all four chambers of the heart, from the mitral valve, and from a papillary muscle of the left ventricle. They all showed the principal histological lesion, a diffuse infiltration of the myocardium by lymphocytes. In places this infiltration was somewhat focal, and in these areas there was some degree of fragmentation of the muscle fibres. The muscle cells were little altered and their nuclei were normal. There was a moderate interstitial oedema. In none of the sections was there any granulomatous tissue, and no polymorphs, plasma cells, or tissue cells took part in the infiltration. No Aschoff nodes were present. The endocardium of the left auricle was grossly thickened but the lymphocytic infiltration did not occur in it. No vegetations were on the mitral valve, and its fine fibrillary pattern was not distorted (figs. 3 and 4).

Sections of the liver confirmed the diagnosis of chronic venous congestion. No evidence of infection was found in the intestine or lungs, and the patch of consolidation appeared to be a small thrombotic infarct.

\section{Comment}

The histology of isolated myocarditis is described, among others, by Saphir (1942), and Saphir, Wile, and Reingold (1944). They recognized two types, the diffuse lymphocytic, and the granulomatous. In only one respect did the present case differ from the classical lymphocytic form, namely in the thickening of the endocardium of the left auricle. In fourteen cases the latter authors gave a full histological description, and in two of these there was endocardial fibrosis associated with a purely lymphocytic infiltration; these were the only cases with this type of infiltration. Thus an endocarditis may be a feature of the condition although it was not included in the classical description.

The histological diagnosis in adults and in the granulomatous types is not so clear. For example Smith and Furth (1943) described three examples but only mentioned the state of coronary vessels in one. Saphir's (1942) description of the granulomatous type included a reference to giant-cell systems, and it is felt that the condition of periarteritis should be excluded in this group.

It is probably safer to reserve the diagnosis of isolated myocarditis for those cases which show the histological lesions of the lymphocytic type.

Differential diagnosis. A number of conditions must be considered in the differential diagnosis.

DIPHTHERIA. There seems to be a close similarity in the microscopical changes in diphtheritic myocarditis and Fiedler's disease. In fact Singer (1932) suggested that all these cases were diphtheritic in origin. However, the absence of diffuse hyaline degeneration and any sign of reparative inflammatory process, together with the lack of any suggestive history or clinical finding, make this diagnosis unlikely.

Rheumatic feVer. There was no clinical evidence of this disease, so rare in infancy; and, histologically, there was no endothelial reaction and there was an absence of Aschoff nodes.

An exactly similar myocarditis has been shown to complicate nearly all the common specific fevers. There is no evidence that any of these diseases was present in this case. Poliomyelitis, which has recently been shown (Saphir and others, 1944) to be complicated by similar changes, was excluded by the clinical state and the absence of histological findings in the nervous system.

BERI-BERI. An example of fatal cardiac beri-beri was recorded in England by Allibone and Baar (1946), but the heart in this case showed gross changes in the muscle fibres and no interstitial changes such as were found in our patient.

SulPhONAMIDE myocaRditis. A number of patients treated with a variety of sulphonamide drugs have been found to show myocardial changes (French and Weller, 1942). Although our patient was given sulphathiazole for five days early in his illness the changes are dissimilar to those described in this condition, since neither eosinophils nor large mononuclears took part in the infiltration.

TrICHINIASIS. Interstitial cellular infiltrations similar to those described have been found in patients suffering from this disease. The heart changes are said to occur between the seventh and twenty-sixth days after infestation. No signs of worm infestation were found on examination of the other organs and skeletal muscle, and there was no eosinophilia.

Glycogen disease was eliminated by clinical and biochemical examinations. The poor response to adrenaline may well have been due to the extensive hepatic lesions of chronic venous congestion.

\section{Classification of Myocarditis}

Saphir and others (1944), in their excellent review of the subject, offer the following classification of myocarditis: (1) foetal (of doubtful entity); (2) myocarditis following contagious and infectious 


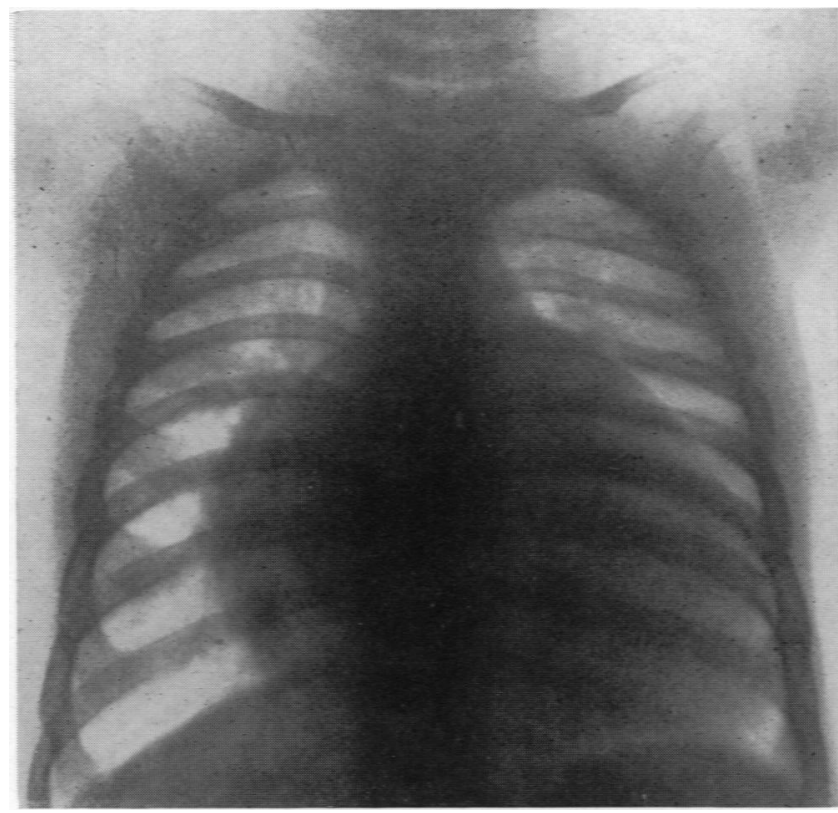

Fig. 1.-Radiograph showing size and shape of the heart.

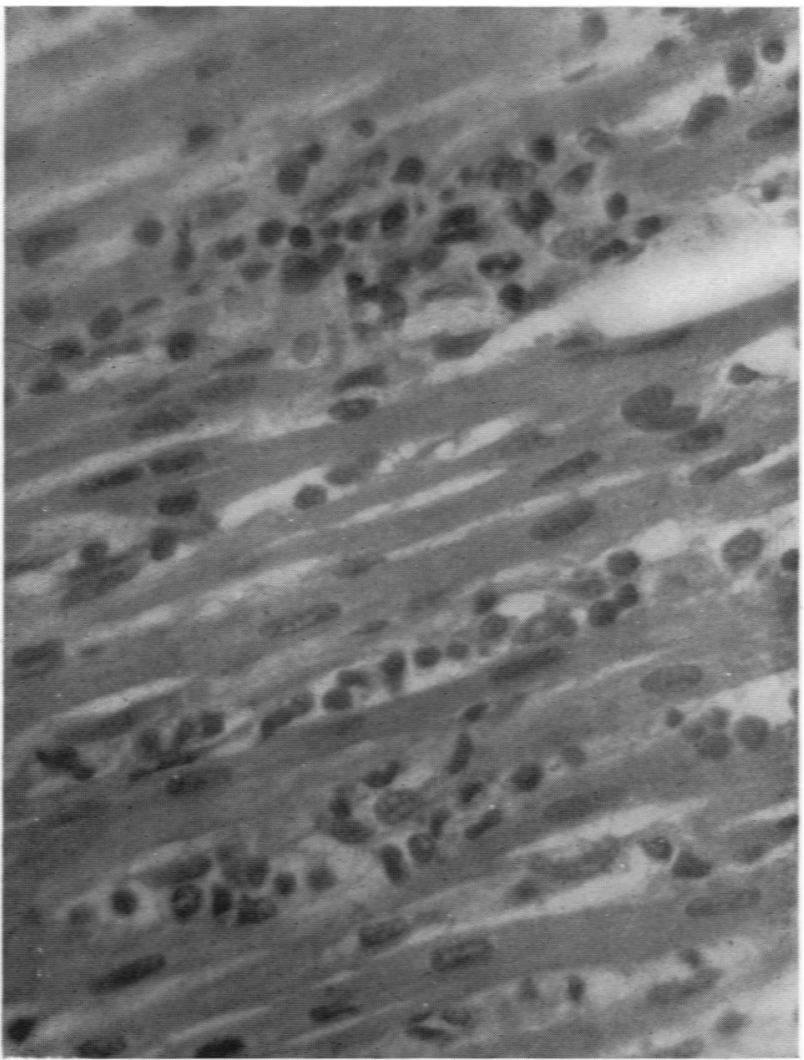

Fig. 3.-Lymphocytic infiltration without gross degeneration of muscle fibres. $\times 650$.

Plate IX

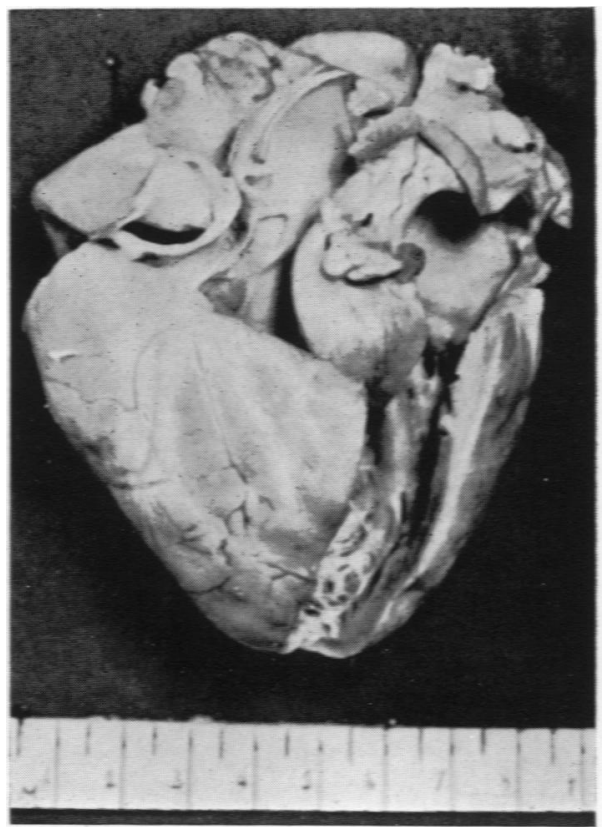

Fig. 2.-The heart, to show size and thickened endocardium of the left auricle.

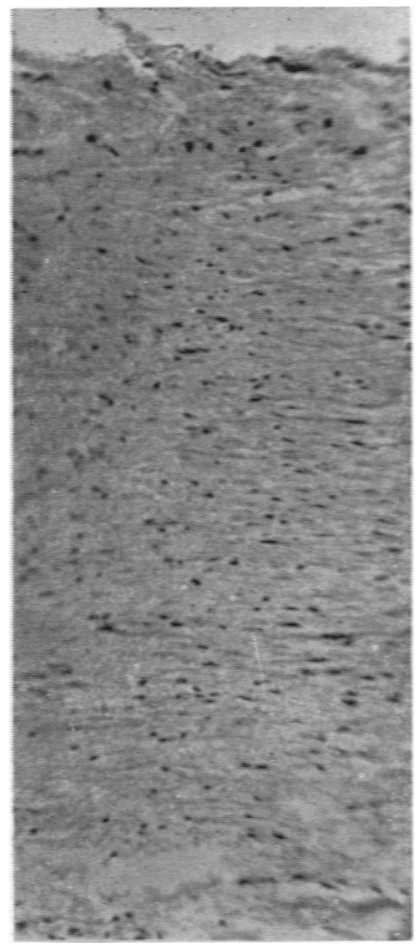

Fig. 4.-Thickened endocardium of left auricle. $\times 150$. 
diseases (a) with endocarditis, and (b) without endocarditis; (3) isolated (Fiedler's) myocarditis; (4) specific myocarditis (rheumatic, tuberculous). They found ninety-seven examples in 1,420 autopsies in a general children's hospital, an incidence of 6.83 per cent. (acute infectious diseases were not admitted to the hospital). Of these ninety-seven, only three were considered to be examples of isolated myocarditis.

The condition may occur in adults and children and most of the recorded cases have occurred in the former.

The diagnosis is difficult, and clinically the cases usually present with increasing myocardial failure for no apparent cause. The temperature is little elevated but tachycardia is constant. Cardiac enlargement and cyanosis are usually seen, and the course is typically rapid with sudden death common, although Baikan (1931) has described acute and chronic types, the latter showing healing and fibrosis. The possibility of resolution of the lesion with a resulting diffuse fibrosis of the myocardium may be considered. Such cases may well include some of the deaths reported in young adults from myocardial fibrosis and regarded as early coronary deficiency.

Conduction changes and alteration of the $T$ waves may be found in cardiograms.

All authorities stress the importance of making careful histological sections of the myocardium, as the changes may be scattered and easily missed if only a few blocks are examined.

The cause of the condition is unknown, though allergy and idiosyncrasy to drugs, arsenic, and (latterly) sulphonamides, have been suggested.
Bernheim-Karrer (1923) found the condition associated with infantile eczema and suggested an allergic cause.

Possibly the ill-defined entity congenital idiopathic cardiac hypertrophy may include examples of this disease. No treatment has proved effective; and, indeed, until the cause is found, none of a specific nature can be attempted.

\section{Summary}

A fatal case of idiopathic (Fiedler's) myocarditis is described. The diagnosis of the condition is discussed and the importance of thorough histological examination of the myocardium in young people who die of unexplained cardiac failure is stressed.

We wish to thank Messrs. D. R. Paton and F. E. R. Byron for help with the photographs, and Miss A. Holding for technical assistance.

\section{ReFERENCES}

Allibone, E. C., and Baar, H. S. (1946). Arch. Dis. Childh., 21, 76.

Baikan, W. S. (1931). Virchow's Arch., 282, 46.

Bernheim-Karrer, J. (1923). Z. Kinderheilk., 35, 120. Fiedler, - . (1899). Festschrift Stadkrankenhauses. Dresden: Friedrichstadt 2.

French, A. J., and Weller, C. V. (1942). Amer. J. Path., $18,112$.

Saphir, O. (1942). Amer. Heart J., 24, 167.

, Wile, S. A., and Reingold, I. M. (1944). Amer. J. Dis. Child., 67, 294.

Singer, L. (1932). Z. Kinderheilk., 53, 660.

Srith, J. J., and Furth, J. (1943). Arch. intern. Med., $71,602$. 